\title{
ARTIGO
}

\section{RESPONSABILIDADE SOCIAL E COMPETÊNCIAS EM INFORMAÇÃO NA BIBLIOTECA MULTINÍVEL}

\author{
SOCIAL RESPONSABILITY AND INFORMATION LITERACY IN THE MULTILEVEL \\ LIBRARY
}

\author{
Jobson Louis Santos de Almeida ${ }^{1}$ \\ Gustavo Henrique de Araújo Freire ${ }^{2}$
}

\footnotetext{
${ }^{1}$ Doutorando em Ciência da Informação (UFPB). E-mail: jobsonlouis@gmail.com.

${ }^{2}$ Professor Associado I (UFRJ).

E-mail: ghafreire@gmail.com.
}

\section{ACESSO ABERTO}

Copyright: Esta obra está licenciada com uma Licença Creative Commons Atribuição 4.0 Internacional. $(\mathrm{(c)}) \mathrm{EY}$

Conflito de interesses: Os autores declaram que não há conflito de interesses.

Financiamento: Não há.

Declaração de Disponibilidade dos dados: Todos os dados relevantes estão disponíveis neste artigo.

Recebido em: 26/02/2019.

Aceito em: 11/04/2019.

Revisado em: 26/05/2019.

\section{Como citar este artigo:}

ALMEIDA, Jobson Louis Santos de; FREIRE, Gustavo Henrique de Araújo. Responsabilidade social e competências em informação na biblioteca multinível. Informação em Pauta, Fortaleza, v. 4, n. 1, p. 9-28, jan./jun. 2019. DOI: https://doi.org/10.32810/25253468.ip.v4i1.2019.40702.9-28.

\section{RESUMO}

Objetiva apresentar reflexão teórica sobre a responsabilidade social e as competências em informação na biblioteca multinível. Discute o lado social da Ciência da Informação e o conceito de biblioteca multinível, perpassando por uma análise do processo de inclusão/exclusão que ocorre a partir do surgimento desse novo tipo de biblioteca com a criação dos Institutos Federais em 2008 no Brasil. Por meio de pesquisa bibliográfica, foi realizado um recorte temporal de 2008 a 2018 no Portal de Periódicos da CAPES, com a finalidade de verificar publicações na Ciência da Informação, seus principais autores e as abordagens existentes que relacionam o desenvolvimento de competências em informação com a responsabilidade social da biblioteca multinível. Foram realizadas buscas por termos isolados e combinados. A escolha dos termos levou em consideração os termos expressos na missão e nos valores comumente encontrados nessas unidades de ensino, obtidos a partir de uma pesquisa documental. 0 artigo aponta estudos e pesquisas viáveis para o campo da Ciência da Informação numa perspectiva social, visando ao aperfeiçoamento da atuação da biblioteca multinível frente às questões de inclusão e a compreensão por parte da comunidade científica sobre o papel social da biblioteca multinível, seus desdobramentos e suas implicações teóricas e práticas na sociedade.

Palavras-chave: Ciência da Informação. Responsabilidade social. Biblioteca multinível. 


\begin{abstract}
It aims to present theoretical reflection on social responsibility and information skills in the multilevel library. It discusses the social side of Information Science and the concept of multilevel library, through an analysis of the inclusion / exclusion process that occurs from the emergence of this new type of library with the creation of the Federal Institutes in 2008 in Brazil. Through a bibliographical research, a temporal cut from 2008 to 2018 was carried out in the CAPES Portal of Periodicals, with the purpose of verifying publications in Information Science, its main authors and the existing approaches that relate the development of information skills with social responsibility of
\end{abstract}

the multilevel library. We searched for isolated and combined terms. The choice of terms took into account the terms expressed in the mission and the values commonly found in these units obtained from a documentary research. The article points out feasible studies and research for the field of Information Science in a social perspective, aiming at improving the performance of the multilevel library in relation to issues of inclusion and understanding by the scientific community about the social role of the multilevel library, its unfolding and its theoretical and practical implications in society.

Keywords: Information Science. Social responsability. Multilevel library.

\section{INTRODUÇÃO}

O presente artigo tem por objetivo apresentar uma reflexão teórica sobre a responsabilidade social e as competências em informação na biblioteca multinível, abordando uma análise do processo de inclusão/exclusão que ocorre a partir do surgimento desse novo tipo de biblioteca. Abrange, também, uma discussão sobre o lado social da Ciência da Informação e o conceito de biblioteca multinível neste contexto.

Logo, o ponto de partida teórico desta nossa discussão é a relação entre o marco teórico para políticas públicas de informação, instituído por Freire (2008), e a abordagem social da Ciência da Informação, apresentada por Righetto, Vitorino e Muriel-Torrado (2018). Neste intervalo de tempo entre as publicações supracitadas, o Brasil vive a primeira década da Rede Federal de Educação Profissional, Científica e Tecnológica (Rede Federal EPCT), instituída a partir da Lei no 11.892, de 29 de dezembro de 2008, considerada um marco de mudança no cenário educacional brasileiro.

Nesta perspectiva, a reflexão é produzida com base na análise da criação dos Institutos Federais, do surgimento de um novo tipo de biblioteca emergente deste cenário, de seus desafios e da literatura científica que discorre sobre a responsabilidade social neste contexto. Esse entendimento fundamenta o questionamento feito na pesquisa, em relação a como o desenvolvimento de competências em informação relaciona-se com a responsabilidade social da biblioteca multinível. 
O presente trabalho foi idealizado e concebido na disciplina Informação e Inclusão Social, componente curricular do Programa de Pós-Graduação em Ciência da Informação da Universidade Federal da Paraíba, e colabora com a linha de pesquisa "Responsabilidade social da biblioteca multinível" do Grupo de Pesquisa Gestão de Projetos em Educação, Ciência, Informação e Tecnologia (PROJECIT), em atividade no Instituto Federal da Paraíba desde 2014.

\section{PROCEDIMENTOS METODOLÓGICOS}

A pesquisa caracteriza-se como de natureza quanti-qualitativa, do tipo descritiva e exploratória, que fez uso das técnicas de pesquisa bibliográfica e pesquisa documental para coleta de dados e de análise de conteúdo para garantir a exequibilidade de suas análises. Foram analisados artigos de periódicos revisados por pares recuperados no Portal de Periódicos da CAPES, uma importante fonte de informação mantida pelo Governo Federal Brasileiro, que reúne as principais bases de dados utilizadas por pesquisadores e cientistas no Brasil.

Quanto aos procedimentos e critérios adotados para busca no referido Portal de Periódicos da CAPES, realizada por meio de acesso institucional às bases de dados, três critérios foram utilizados para a busca e seleção dos artigos, a saber: termos de busca, tipo de recurso e texto revisado por pares. Não foram excluídas as publicações recuperadas em língua estrangeira para fins de análise nesta investigação. Os termos de busca utilizados foram os seguintes: "biblioteca multinível", "responsabilidade social", “cidadania”, "Instituto Federal”, "Educação Profissional”, "inclusão social”, "exclusão social", "vulnerabilidade", "sociedade inclusiva" e "compromisso social". A busca foi realizada por termos isolados e por combinação entre si, conforme possibilidades dos recursos da própria ferramenta de busca. Quanto ao tipo de recurso foram considerados os artigos científicos. A partir dos critérios supracitados, optou-se por analisar apenas os artigos de periódicos revisados por pares, sendo recuperados em sua totalidade $\mathbf{5 2 8}$ publicações desta natureza, com relação temática aos termos adotados na etapa de busca. Deste total de publicações recuperadas no Portal de Periódicos da CAPES, foram identificados 15 trabalhos relevantes para o presente estudo, em acordo com o objetivo traçado. 
No que tange à pesquisa documental, realizou-se por amostragem a identificação da missão e dos valores dos Institutos Federais que possuem biblioteca multinível no Brasil, viabilizada por meio de consulta aos seus portais institucionais na web.

Posterior à pesquisa bibliográfica e documental, procedeu-se a análise de conteúdo. Esta, de acordo com Vergara (2010), veio sendo amplamente utilizada e desenvolvida desde o começo do século 20 como uma técnica aplicada, principalmente, no tratamento de material jornalístico. Contudo, neste início de século 21, observa-se também aplicação desta técnica para a análise de documentos institucionais, transcrições de entrevistas, artigos científicos, entre outras situações em que se faz necessário o emprego de uma técnica para tratar dados e identificar o conteúdo de mensagens, textos e comunicações em geral, tanto em abordagens quantitativas, quanto qualitativas, ou mesmo quanti-qualitativas.

A aplicação da análise de conteúdo, neste trabalho, contribuiu para identificar, categorizar e compreender as abordagens temáticas e de cunho teórico-conceitual presentes nas publicações recuperadas por meio do Portal de Periódicos da CAPES, em texto completo. Todos estes procedimentos viabilizaram a construção de uma reflexão teórica sobre a responsabilidade social e as competências em informação na biblioteca multinível.

Na primeira fase, denominada pré-análise, foram realizadas a tradução, quando necessário, e a leitura dos resumos do material recuperado no Portal de Periódicos da CAPES, com base em três critérios de refinamento permitidos nesta ferramenta, a saber: termos de busca, tipo de recurso e texto revisado por pares. Com base em Bardin (1977), foram obedecidos os princípios de exaustividade, representatividade, homogeneidade e pertinência, que são facilmente percebidos ao observamos que, nesta pesquisa, foi decidido analisar todos os artigos completos e revisados por pares recuperados nas bases de dados, que se encontram, preferencialmente, inseridos ou relacionados ao campo científico da Ciência da Informação, atendendo ao objetivo e propósito da investigação.

A segunda fase consistiu na exploração do material, considerando a análise de todos os artigos na íntegra, sem prejuízo na tradução. E a terceira fase, de inferências, consistiu em interpretação do conteúdo e na discussão dos resultados, cuja apresentação dar-se-á nas três seções seguintes, que versam sobre a primeira década da biblioteca multinível, a produção científica na Ciência da Informação sobre 
competências em informação e responsabilidade social, e as perspectivas para a responsabilidade social da biblioteca multinível, incluindo as contribuições já extraídas da literatura científica e as possibilidades de estudos e pesquisas a serem desenvolvidos na Ciência da Informação brasileira a partir das informações obtidas por meio da análise realizada.

\section{A PRIMEIRA DÉCADA DA BIBLIOTECA MULTINíVEL NO BRASIL (2008-2018)}

No Brasil, os Institutos Federais de Educação, Ciência e Tecnologia foram criados pela Lei $\mathrm{n}^{\circ} 11.982$, de 29 de dezembro de 2008, que instituiu essa reestruturação da Rede Federal de Educação Profissional, Científica e Tecnológica. Aqui denominamos reestruturação, pois a Rede Federal EPCT já existe há pouco mais de um século, oriunda das Escolas de Aprendizes e Artífices, criadas em 1909, pelo Decreto no 7.566, que também eram custeadas pela União (BRASIL, 2008).

As supracitadas escolas passaram por várias mudanças ao longo do tempo. Surgiram Escolas Técnicas e Agrotécnicas em 1959, Centros Federais de Educação Tecnológica (CEFETs) em 1978, reunificando as Escolas Técnicas e Agrotécnicas em 1994, e uma Universidade Tecnológica Federal no Estado do Paraná em 2005, que é originada de um CEFET. Embora a Rede Federal de Educação Profissional, Científica e Tecnológica comemore no ano de 2018 seus 109 anos de existência, os Institutos Federais de Educação, Ciência e Tecnologia só foram criados em 2008, existindo, portanto, há apenas 10 anos, o que nos leva a inferir que sua identidade ainda está em construção dada a recente criação, muito embora a imagem organizacional que é tida pela sociedade brasileira ainda traz como referencial o ensino técnico por excelência. Tal representação mental vem possivelmente sofrendo alterações com o aumento da oferta da educação superior nessas instituições nessa primeira década de existência e atuação, sobretudo quando percebemos que instituições com tradição na oferta de ensino técnico passam a ofertar também licenciaturas, pós-graduação e uma diversidade maior de níveis de ensino que não é observado em nenhum outro tipo de instituição educacional existente na sociedade brasileira.

A partir de dezembro de 2008, 31 centros federais de educação tecnológica (CEFETs), 75 unidades descentralizadas de ensino (UNEDs), 39 escolas agrotécnicas, 7 escolas técnicas federais e 8 escolas vinculadas a universidades deixaram de existir para 
formar os Institutos Federais de Educação, Ciência e Tecnologia (BRASIL, 2008). Atualmente, existem 38 Institutos Federais (IFs) no Brasil, oferecendo cursos de qualificação profissional de curta duração, cursos de educação de jovens e adultos (PROEJA), ensino médio integrado, cursos técnicos integrados e subsequentes, cursos superiores de tecnologia, bacharelados e licenciaturas, além de pós-graduação lato e stricto sensu. De acordo com o Ministério da Educação (BRASIL, 2018), ainda há instituições que fazem parte desta Rede, mas que não aderiram ao formato Instituto Federal e que oferecem educação profissional em todos os níveis, a saber: dois centros federais, 25 escolas técnicas vinculadas a Universidades, o Colégio Pedro II e 01 Universidade Tecnológica (com 11 campi) no Estado do Paraná.

Para fins desta investigação, foram considerados relevantes os dados sobre os Institutos Federais de Educação, Ciência e Tecnologia, por representarem a maioria das instituições da Rede Federal EPCT e por serem o formato de instituição pública de ensino mais recente criado no Brasil e também inovador do ponto de vista de seu projeto político-pedagógico, sem igual modelo no mundo, o que representa inúmeros desafios para as bibliotecas e os bibliotecários destas organizações.

Os IFs possibilitam o acesso à Educação Profissional e Tecnológica por meio da oferta de cursos em diversos níveis de ensino, a saber: Profissionalizante, Educação de Jovens e Adultos, Médio, Técnico, Superior e Pós-Graduação. E nas mais diversas modalidades que se enquadram nos níveis citados anteriormente, a saber: Médio Integrado ao Técnico, Técnico Subsequente, Superior (Tecnológico, Bacharelado e Licenciatura), Pós-Graduação (Lato e Stricto Sensu), além de cursos profissionalizantes de Formação Inicial e Continuada (FIC), o Programa de Educação de Jovens e Adultos (PROEJA), entre outras práticas de educação profissional e tecnológica em programas e projetos governamentais, tais como o Programa de Acesso ao Ensino Técnico e ao Emprego (PRONATEC) e o Programa Mulheres Mil. Este universo diferenciado e abrangente de níveis de ensino promove um desafio complexo às bibliotecas, que nos últimos anos têm repensado sua própria identidade, suas ações e suas práticas no contexto dessa nova configuração das instituições federais de ensino profissional e tecnológico.

Garcia, Barbosa e Oliveira (2011, p. 115), na discussão sobre o contexto das identidades e do cenário político gerencial da biblioteca pública brasileira, defendem que a identidade organizacional de uma biblioteca é compreendida como um conjunto 
de "crenças e valores organizacionais, o conhecimento explícito e formal da biblioteca enquanto organização e sua visão de futuro". Esse também é o entendimento utilizado para a discussão da identidade da biblioteca multinível neste presente estudo.

Becker e Faqueti (2015) realizaram um panorama das bibliotecas da Rede Federal de Educação Profissional, Científica e Tecnológica e afirmam que, devido às instituições que compõem essa Rede serem centenárias, a sua história, bem como a de suas bibliotecas, já é marcada por mudanças estruturais e funcionais que ocorreram ao longo desses anos. A reorganização ocorrida em 2008, a partir da Lei no 11.892, que instituiu a Rede Federal EPCT e criou os Institutos Federais, resultou em uma mudança significativa para as bibliotecas dessas instituições, a saber: a criação de uma nova tipologia para essas bibliotecas, diretamente vinculada ao tipo de usuários que estas atendem. As autoras reafirmam ser necessário, portanto, analisar a tipologia das bibliotecas da Rede para se compreender melhor a identidade delas e chegar a um consenso. Considerando a necessidade de uma posição intermediária nesta discussão, Becker e Faqueti (2015) optaram pela visão de que as bibliotecas dos IFs são mistas, ou seja, devem ser entendidas como bibliotecas escolar e universitária, pois suas maiores demandas centram-se no universo de usuários compostos por estudantes de nível médio e superior. Apesar dessa posição intermediária, elas concordam com Santos, Hoffmann e Boccato (2011, p. 1), para quem as bibliotecas dos Institutos Federais "[...] caminham na busca de sua construção identitária, abarcando uma junção de tipologias e olhares a serem refinados e construídos".

Contudo, sabe-se que as bibliotecas dos IFs no Brasil ainda não possuem uma identidade consensualmente definida de acordo com suas funções e finalidade, por não encontrar na literatura menção a um tipo de biblioteca que abranja toda complexidade deste recém-criado perfil de unidade de informação, com exceção de Almeida (2015) em nível de dissertação de Mestrado, na qual evidencia que, embora essas unidades de informação atendam aos usuários do Nível Médio e do Nível Superior, em sua maioria, ainda há os que refutam a ideia de classificá-las como biblioteca escolar-universitária ou híbrida ou mista, por representar uma possível fragilidade identitária ou por restringir o seu espaço de atuação. Essa dificuldade de classificação apresentada por alguns é compreensível, pois, no contexto dos IFs, as bibliotecas prestam serviços de informação aos mais variados grupos de usuários, quais sejam, usuários vinculados aos diversos níveis e modalidades de ensino já citados. 
Nesse sentido, ainda não existe um consenso entre os bibliotecários sobre qual seria a denominação mais adequada para traduzir um espaço de informação que atende a múltiplos grupos de usuários com perfis diferenciados. Na literatura científica, nos encontros profissionais e no âmbito das listas de discussão por e-mail alguns defendem as terminologias "biblioteca híbrida" ou "biblioteca mista" como solução para o não enquadramento desta biblioteca nas tipologias existentes e consolidadas pela literatura e pela prática profissional. Além disso, mais recentemente, há a proposta inédita de adoção da terminologia biblioteca multinível para as bibliotecas dos IFs, idealizada pioneiramente por Moutinho (2014, p. 71) e estudada com maior detalhamento e disseminada por Almeida (2015), em que a biblioteca é percebida como uma organização que atende às necessidades de um público de diferentes níveis de processos formativos (nível médio, técnico e superior) e, consequentemente, diferentes níveis de necessidades e competências informacionais. No entanto, apesar da falta de consenso quanto à identidade dessas bibliotecas segundo funções e finalidade, não se pode negar que as bibliotecas de IFs atendem aos diversos grupos de usuários mencionados, e a terminologia proposta apresenta-se como coerente e única alternativa até então inovadora e abrangente proposta na literatura científica.

Conceitualmente, biblioteca multinível é toda aquela unidade de informação que, quanto à finalidade, atende aos usuários de diversos níveis de ensino. Tem por objetivo atender às necessidades de estudo, consulta e pesquisa de professores, servidores técnico-administrativos e alunos em nível profissionalizante, médio, técnico, superior de graduação e pós-graduação (lato e stricto sensu). Segundo a organização das coleções, assemelham-se às universitárias, podendo ser centralizadas ou descentralizadas, porém este arranjo ainda não é regra e nem padrão. Como principal exemplo de biblioteca multinível, temos as bibliotecas das instituições da Rede Federal de Educação Profissional, Científica e Tecnológica no Brasil. Portanto, é um novo tipo de biblioteca que já existe em expressivo número, já que, segundo o panorama de Becker e Faqueti (2015), temos pelo menos 317 bibliotecas no âmbito desta Rede Federal.

Partindo desta premissa, considera-se que a biblioteca nos Institutos Federais de Educação, Ciência e Tecnologia podem ser do tipo biblioteca multinível, por compreender que a biblioteca atende, em sua maioria, aos usuários de todos os diversos níveis de ensino supracitados e por defender que a definição da identidade de uma biblioteca dessa complexidade é relevante para inseri-la no campo científico com 
propriedade, e para nortear as discussões entre os bibliotecários que dela fazem parte quanto às práticas e às políticas adotadas para seus próprios serviços de informação.

Nesta primeira década de existência e atuação da biblioteca multinível no Brasil, os desafios postos a ela assemelham-se aos desafios postos às suas instituições mantenedoras. Estas assumem o compromisso de intervenção social no território em que estão inseridas, identificando problemas e gerando soluções técnicas e tecnológicas para o desenvolvimento regional sustentável com inclusão social, conforme expresso nas missões destes Institutos. A própria escolha dos cursos a serem ofertados, por exemplo, é realizada por meio de audiências públicas e escutas das representações e lideranças da sociedade civil. Neste contexto, faz-se necessário observar a relação conceitual entre a responsabilidade social destas bibliotecas neste novo cenário, sobretudo no tocante ao desenvolvimento de competências em informação.

\section{POLÍtICAS DE INFORMAÇÃO, RESPONSABILIDADE SOCIAL E COMPETÊNCIAS EM INFORMAÇÃO: interseções conceituais}

Por meio de pesquisa bibliográfica, realizou-se um recorte temporal de 2008 a 2018 no Portal de Periódicos da CAPES, com a finalidade de verificar se há publicações no contexto da Ciência da Informação, seus principais autores e as abordagens existentes que relacionam o desenvolvimento de competências em informação com a responsabilidade social da biblioteca multinível. 0 estudo também mapeou, por amostragem, a missão e os valores dos Institutos Federais que possuem biblioteca multinível no Brasil, por meio de consulta aos seus portais institucionais na web. Nesta seção, apresentam-se os resultados obtidos por meio da pesquisa realizada.

Como primeiro resultado da investigação, verificou-se que não há publicações no contexto da Ciência da Informação que relacionem o desenvolvimento de competências em informação com a responsabilidade social da biblioteca multinível. No entanto, observou-se que há 15 publicações no Portal de Periódicos da CAPES que versam sobre a responsabilidade social das instituições pertencentes à Rede Federal EPCT no intervalo de 2008 a 2018. A seguir, será apresentada, portanto, reflexão que toma por base esse conjunto de publicações, relacionando-as com autores do campo da Ciência da Informação que discorrem sobre competências em informação e políticas de informação neste mesmo período de tempo, possibilitando estabelecer algumas interseções 
conceituais que atendem ao objetivo desta investigação e oportunizam traçar perspectivas para o desenvolvimento de novos estudos, sobretudo com foco no desenvolvimento da biblioteca multinível.

No Quadro 1 é exibida a categorização dos 15 trabalhos que versam sobre responsabilidade social no Portal de Periódicos da CAPES, destacando o ano e a autoria, com indicação da procedência institucional. Verificou-se que 7 das 15 publicações são de autoria de pesquisadores vinculados a instituições de ensino nordestinas, com predominância de publicações oriundas de instituições do Rio Grande do Norte, principalmente do IFRN. Tal fato pode ser relacionado ao predomínio de políticas de inclusão social direcionadas principalmente para as regiões Norte e Nordeste do país durante o Governo Lula da Silva (2003-2010), a exemplo do Programa Mulheres Mil, que, de acordo com Furtado e Oliveira (2013, p. 238), consistiu em uma das políticas que teve por finalidade promover a inclusão social por meio da formação profissional, tendo como alvo as mulheres desfavorecidas e em condição de risco das regiões Norte e Nordeste. Este programa ficou conhecido por almejar o desenvolvimento da capacidade produtiva dessas mulheres, incluindo a melhoria da qualidade de vida de suas famílias, de suas comunidades e no crescimento econômico sustentável da região onde vivem.

Quadro 1 - Categorização por ano, autoria e instituição.

\begin{tabular}{|c|c|c|}
\hline ANO & AUTORIA & ORIGEM INSTITUCIONAL \\
\hline 2008 & Gomes & CEFET-RN \\
\hline \multirow{2}{*}{2010} & Tavares e Gomes & IFF \\
\cline { 2 - 3 } & Medeiros e Tabosa & IFRN \\
\hline \multirow{2}{*}{2012} & Furtado et al. & IF Sudeste MG \\
\cline { 2 - 3 } & Pereira e Guedes & IFRN \\
\hline 2013 & Fredenhagem et al. & IFB \\
\hline 2014 & Furtado e Oliveira & IFPB \\
\hline \multirow{3}{*}{2015} & Maschio & UFSM Sul Rio-Grandense \\
\cline { 2 - 3 } & Bezerra et al. & IFF \\
\cline { 2 - 3 } & Correa e Silva & Pref. Mun. de Santa Maria Madalena \\
\cline { 2 - 3 } & Hora & IFMA \\
\hline \multirow{2}{*}{2016} & Lopes e Moura & IFRN \\
\cline { 2 - 3 } & Vitorette e Castro & IFG \\
\hline \multirow{2}{*}{2017} & Antunes et al. & IFPR \\
& Silva Júnior et al. & IFRO \\
& & UFAL \\
\hline
\end{tabular}

Fonte: Dados da pesquisa (2019).

Verificou-se que nenhuma dessas publicações pertence ao campo da Ciência da Informação. Das 15 publicações, 8 estão vinculadas diretamente ao campo da Educação, e as demais publicações oriundas principalmente de áreas que, nos Institutos Federais, 
estão sob o formato de cursos de licenciatura, a saber: Física, Química, Biologia, História, Geografia e Letras. Há pelos menos uma publicação vinculada também às Ciências da Saúde, Administração e Engenharia, com base na procedência institucional da autoria das obras. Este dado nos leva a perceber que a inclusão de cursos de cunho humanístico, tais como são as licenciaturas, trouxe uma maior dedicação às questões sociais por parte dessas instituições, que sempre desenvolveram estudos tecnicistas em sua maioria.

Quanto a abordagem temática dos 15 trabalhos analisados, conforme categorizado no Quadro 2, verificamos predominância dos seguintes temas, agrupados em seis categorias, a saber: inclusão educacional e/ou no mundo do trabalho; cidadania, vulnerabilidade e transformação social; evasão escolar; responsabilidade socioambiental, desenvolvimento sustentável e responsabilidade social das organizações.

Quadro 2 - Categorização por temáticas mais frequentes.

\begin{tabular}{|c|c|c|}
\hline TEMA & $\begin{array}{c}\text { PUBLICAÇõES } \\
\text { (AUTORIA/ANO/INSTITUIÇÃO) }\end{array}$ & QUANTIDADE \\
\hline \multirow{4}{*}{$\begin{array}{l}\text { Inclusão educacional } \\
\text { e/ou no mundo do } \\
\text { trabalho }\end{array}$} & Tavares e Gomes (2010) - IFF & \multirow{4}{*}{04 (quatro) } \\
\hline & Bezerra et al. (2015) - UFSM & \\
\hline & Hora (2015) - IFMA & \\
\hline & Vitorette e Castro (2016) - IFG & \\
\hline \multirow{4}{*}{$\begin{array}{c}\text { Cidadania, } \\
\text { Vulnerabilidade e } \\
\text { Transformação } \\
\text { Social. }\end{array}$} & Furtado et al. (2012) - IF Sudeste MG & \multirow{4}{*}{04 (quatro) } \\
\hline & Furtado e Oliveira (2013) - IFPB & \\
\hline & Maschio (2014) - IF Sul Rio-Grandense & \\
\hline & Antunes et al. (2016) - IFPR & \\
\hline \multirow{3}{*}{ Evasão escolar } & Gomes (2008) - CEFET-RN & \multirow{3}{*}{03 (três) } \\
\hline & Fredenhagem et al. (2012) - IFB & \\
\hline & $\begin{array}{l}\text { Silva Júnior et al. (2017) - IFRO, UFAL e } \\
\text { Faculdade de Educação de Porto Velho }\end{array}$ & \\
\hline \multirow{2}{*}{$\begin{array}{l}\text { Responsabilidade } \\
\text { socioambiental }\end{array}$} & Medeiros e Tabosa (2010) - IFRN & \multirow{2}{*}{02 (dois) } \\
\hline & Lopes e Moura (2015) - IFRN & \\
\hline $\begin{array}{l}\text { Desenvolvimento } \\
\text { sustentável }\end{array}$ & $\begin{array}{c}\text { Correa e Silva (2015) - IFF e Pref. Mun. de Santa Maria } \\
\text { Madalena }\end{array}$ & 01 (um) \\
\hline $\begin{array}{c}\text { Responsabilidade } \\
\text { social das } \\
\text { organizações } \\
\end{array}$ & Pereira e Guedes (2012) - IFRN & 01 (um) \\
\hline
\end{tabular}

Fonte: Dados da pesquisa (2019). 
A inclusão educacional e no mundo do trabalho está intimamente ligada à missão e aos valores dos Institutos Federais. Analisando as missões e os valores contidos em 25 portais destas instituições, por amostragem representativa das cinco regiões geográficas do país, observou-se maior frequência de expressões como: formar cidadãos críticos para o mundo do trabalho; contribuir para o desenvolvimento sustentável; inserção social; compromisso com a transformação social; educação inclusiva e de qualidade; dignidade humana; justiça social; educar para a vida e para o trabalho; promover educação básica, profissional e superior, nos diferentes níveis e modalidades, em benefício da sociedade; e formação de cidadãos para atuarem no mundo do trabalho e na construção de uma sociedade inclusiva, justa, sustentável e democrática.

Quanto a este tema, observamos a partir de Tavares e Gomes (2010) e Bezerra et al. (2015), respectivamente, que os Institutos Federais possuem relevante papel na inclusão de alunos portadores de transtornos de aprendizagem, assim como na inclusão de indivíduos no mundo do trabalho e no acesso aos variados bens culturais, a exemplo do PROEJA como um programa de inclusão de jovens e adultos no sistema público de educação profissional, com a finalidade de profissionalização e inclusão social, tendo em vista que esse programa faz parte de um projeto nacional de desenvolvimento.

Vitorette e Castro (2016) trazem uma outra ação com fins de inclusão adotadas nos IFs, que é a substituição da forma de ingresso nos cursos, que tradicionalmente é realizada por provas e, recentemente, vêm sendo adotadas formas alternativas que levam em consideração a inscrição gratuita, sorteio, palestra e entrevista. Uma das práticas que vem sendo adotada é a análise curricular em substituição à prova tradicional, conforme já ocorre, por exemplo, no Instituto Federal da Paraíba para acesso aos cursos técnicos. No entanto, Hora (2015, p. 73), buscando compreender o caráter democrático e inclusivo da atual multiplicidade de ofertas formativas que compõem a política educacional dos Institutos Federais, apresenta o outro lado da moeda, ao demonstrar que:

[...] as estratégias de inclusão social instituem trajetórias subordinadas de qualificação profissional por meio da diversificação de ofertas educacionais que criam a fantasia do discurso de acesso democrático à escola, intensificando no âmbito destes espaços desigualdade no acesso efetivo e democrático ao conhecimento.

Hora (2015, p. 86) conclui seu estudo afirmando que: 
[...] a ampliação cada vez mais diversificada de programas de qualificação para os trabalhadores no âmbito dos Institutos Federais, ora com elevação da escolaridade integrada à qualificação profissional, ora apenas com cursos de caráter profissionalizante, apresentam como característica comum a distribuição desigual do saber científico e do saber prático, a redução dos conteúdos e do tempo de escolarização. Nesse sentido, os programas destinados à formação do trabalhador, colaboram, na maioria das vezes para a melhoria da autoestima, elevação da escolaridade e para conferir mudanças no cotidiano da vida, nas relações com as pessoas e com a família. [...] A diversificação de ofertas formativas também potencializa a falsa ideia de que há uma relação imediata entre elevação de escolaridade ou formação profissional e obtenção de emprego e renda. Este discurso atinge, sobretudo, as frações de classe mais vulneráveis e exploradas. [...] Esta perspectiva sobre o papel da escola remete uma função que ela não cumpre, pois se o atual sistema de produção não consegue gerar emprego e renda para todos, como a instituição escolar conseguirá promover aquilo que o próprio sistema em que ela está inserida não oferece em sua atual fase de acumulação, o toyotismo? A dualidade estrutural de novo tipo cria a fantasia da inclusão social e democratização do acesso à educação de qualidade a todas as frações de classes. Compreender esta dinâmica é fundamental para fortalecer o processo de construção de resistência e luta em defesa de uma educação pública que de fato confira um espaço democrático e privilegiado para formação integral à classe trabalhadora, nos princípios do Trabalho, da Ciência e da Cultura.

Quando à cidadania, vulnerabilidade social e transformação social, Furtado et al. (2012), Furtado e Oliveira (2013), Maschio (2014) e Antunes et al. (2016) discorrem todos sobre o Programa Mulheres Mil, que se consistiu em uma política social de inclusão, por meio do qual as mulheres em situação de vulnerabilidade social têm acesso à educação profissional, emprego e renda. Furtado et al. (2012, p. 179) dizem que a

[...] vulnerabilidade social pode ser entendida como um espelho das condições de bem-estar social. Quando se fala em bem-estar social englobam-se dois subcomponentes: o bem-estar econômico (salário/renda) e o bem-estar sóciodemográfico (moradia, saúde, alimentação, educação, lazer e outros). Todavia, cada pessoa pode reagir diferentemente a situações semelhantes. A participação no Programa poderá constituir-se em fator de mudança na vida dessas mulheres por favorecer a inclusão social, por meio da oferta de formação focada na autonomia e na criação de alternativas para a inserção no mundo do trabalho. Dessa maneira, poderá influenciar na satisfação com a vida, felicidade, afeto positivo e negativo das participantes.

Outro dado relevante apresentado por Furtado et al. (2012, p. 185) sobre exclusão social é que

[...] as mulheres, apesar de terem aumentado a participação no mercado de trabalho e melhorado o grau de instrução, continuam encabeçando a lista. Elas representam $55 \%$ da população mundial, mas, no entanto, apenas $40 \%$ estão no mercado de trabalho e representam apenas $10 \%$ da renda do mundo. A pobreza no mundo tem, portanto, sexo. 0 termo exclusão social tem sentido temporal e espacial: um grupo social está excluído segundo determinado espaço geográfico ou em relação à estrutura e conjuntura econômica e social do país a que pertence. No Brasil, esse termo está relacionado principalmente à 
situação de pobreza, uma vez que as pessoas nessa condição constituem grupos em exclusão social, porque se encontram em risco pessoal e social, ou seja, excluídas das políticas sociais básicas (trabalho, educação, saúde, habitação, alimentação). Assim, à medida que o indivíduo encontra dificuldades para cumprir satisfatoriamente suas tarefas básicas de socialização e de amparo/serviços, criam-se situações de vulnerabilidade.

Em tempos de imigração e crises nas fronteiras dos países em todo o mundo, Maschio (2014) traz uma experiência inédita e única no âmbito do Programa Mulheres Mil Binacional, que atendeu mulheres brasileiras e uruguaias, em que as alunas receberam certificados expedidos pelo IFSul e pelo MIDES (Ministerio del Desarrollo Social - do Uruguai), reconhecidos dos dois lados da fronteira. De acordo com Maschio (2014, p. 76),

[...] [a] proposta do projeto Mulheres Mil Binacional foi apresentada, em primeira mão, em uma das reuniões periódicas da Comissão Binacional de Assuntos Sociais Livramento/Rivera, espaço interlocutor de políticas públicas sociais para as cidades gêmeas, em abril de 2012. O Programa Nacional Mulheres Mil assumiria o compromisso de contribuir com a elevação da escolaridade e propiciar uma qualificação profissional, primando sempre pelos valores humanos e o exercício da cidadania de mulheres que vivem na fronteira entre Sant'Ana do Livramento, no Brasil, e Rivera, no Uruguai.

A demonstração do quão esse programa foi relevante para o combate à violência doméstica e ao tráfico de mulheres, para o incentivo à cultura do livro e da leitura e, principalmente, para a socialização e inserção social dessas mulheres que se encontravam em vulnerabilidade social é expressa em Maschio (2014, p. 85), ao dizer que:

O Mulheres Mil Binacional se tornou uma referência de política pública para as mulheres da fronteira, bem como de política para a integração dos dois países. Uma das primeiras ações na sociedade foi a participação das estudantes na caminhada binacional contra a violência doméstica. Com a camiseta do programa, mulheres brasileiras e uruguaias passaram pelas ruas de ambos os países pedindo paz e compreensão nos lares, entre as famílias. Durante a IV Feira Binacional do Livro, puderam participar de palestras sobre o tráfico de mulheres e crianças e todas levaram livros (doados) e folhetos informativos para as suas casas. Ainda participaram ativamente, recebendo as colegas de outros campus no I encontro Mulheres Mil do IFSul. No entanto, de todas essas ações praticadas e os sentimentos que fluíram, nada irá superar o conhecer-se e o reconhecer-se, proporcionados pelas parcerias firmadas entre instituições e pessoas. Contatos novos, reencontros e encontros que só foram possíveis pela causa Mulheres Mil. Palestrantes de um lado e do outro da fronteira trocaram conhecimentos e tiveram que conviver durante as aulas e reuniões do programa; órgãos públicos, secretárias municipais, o IFSul e as escolas parceiras, os consulados com a polícia federal, os bancos, as empresas de ônibus, os alunos dos cursos técnicos, as alunas do programa, os professores... todos tiveram que dialogar, compartilhar e ajudar no desenvolvimento do primeiro Mulheres Mil Binacional do país. 
Em abordagem mais recente, Antunes et al. (2016, p. 158) afirmam que a participação dessas mulheres nas aulas possibilitou para elas mesmas a elevação da autoestima e a mudança de perspectivas de vida, pois "passaram a se enxergar capazes de serem alguém, de realizarem sonhos e terem uma vida melhor". Com maior respaldo de outros estudos e da execução do Programa em outros Estados, os autores também afirmam que estes resultados positivos têm sido observados em outros Institutos Federais que aderiram ao Programa Mulheres Mil.

Quanto à evasão escolar, Gomes (2008), Fredenhagem et al. (2012) e Silva Júnior et al. (2017) apontam para questões muito importantes de exclusão social que ocorrem no espaço onde deveria ser o mais integrador da sociedade: a escola. Dentre as questões apresentadas destacam-se: a adoção de políticas específicas para o ingresso de estudantes de escolas públicas; a prática da inclusão das pessoas com necessidades educacionais especiais (PNEE); e os vários problemas que culminam na evasão escolar, principalmente a carência básica, como alimentação fruto de problemas financeiros, cansaço devido a poucas horas de sono ou mesmo pela dificuldade de conciliar trabalho/estudo/distâncias/trânsito, os quais dão origem a outros problemas, como dificuldade de acompanhar o curso, desinteresse (gerados, por sua vez, pelo excesso de faltas), constituindo-se em uma cadeia de efeitos que culminam na evasão. Fredenhagem et al. (2012, p. 18) destacam que se por um lado os institutos federais cumprem sua missão de abrigar grande parcela da classe social menos favorecida, por outro aponta-se para a "necessidade e compromisso de incluir na pauta da estrutura dos campi um efetivo trabalho social de sustentação e elevação cultural dessa demanda, que também representa grande parte da força de trabalho do país". Silva Júnior et al. (2017, p. 211) defendem como solução a atuação integrativa entre os diferentes sujeitos e agentes do contexto educacional dos IFs, afirmando que

A educação profissional de qualidade se apresenta como um canal capaz de inserir os alunos de classes sociais menos favorecidas na sociedade e no setor produtivo, possibilitando a diminuição das diferenças sociais e econômicas, desfrutando de uma vida mais digna e isonômica. Precisamos tratar o problema da evasão escolar de forma integrada e participativa, com vistas a sua superação. Dessa forma, compete a todos integrantes, professores, alunos, coordenadores, tutores, escola, sociedade e Poder Público desenvolver suas ações visando a mudança da realidade educacional, proporcionando a formação intelectual do cidadão e sua inserção na sociedade. 
Por fim, e não menos importantes, na ampla teia de discussão sobre inclusão e exclusão social, temas apresentam-se cada vez mais frequentes e necessários, tais como a responsabilidade socioambiental, o desenvolvimento sustentável e a responsabilidade social das organizações, conforme podemos observar por meio dos estudos de Medeiros e Tabosa (2010); Pereira e Guedes (2012); Lopes e Moura (2015); e Correa e Silva (2015).

Em todo este cenário podemos perceber a possibilidade de inclusão do bibliotecário com todo o seu potencial educador e transformador por meio da leitura, da cultura e da informação, sobretudo quando atentamos para a sua capacidade de contribuir no desenvolvimento de competências em informação nestes espaços, considerando seu regime e suas políticas de informação.

Para Freire (2008, p. 198), a gestão de recursos informacionais pode favorecer o acesso a serviços e tecnologias, e a democratização destas constitui elemento fundamental nas políticas públicas de inclusão social. Contextualizando essa discussão no campo da Ciência da Informação no Brasil, Freire (2008) defende que as políticas de informação, como instrumento regulador, podem vir a contribuir para a melhoria do nível educacional, cultural e político da sociedade, implicando no exercício pleno da cidadania. Portanto, fica evidente que não podemos dissociar as políticas de informação da discussão sobre responsabilidade social das bibliotecas nos Institutos Federais. Corroborando com Freire (2008, p. 200), afirmamos que se constitui papel da Ciência da Informação o desenvolvimento de embasamento teórico para propor e discutir ações de informação que efetivamente venham a contribuir para a promoção de políticas de informação possíveis de serem utilizadas como instrumentos de gestão de recursos de informação neste contexto de inclusão social e digital.

No campo da Ciência da Informação, paralelo à criação da Rede Federal EPCT, verificou-se nesta pesquisa que, ainda em 2018, não há estudos na Ciência da Informação que versem sobre a responsabilidade social das bibliotecas dos IFs, aqui denominadas bibliotecas multinível.

Entretanto, é possível perceber que a Ciência da Informação brasileira já começa a compreender e disseminar a relação possível entre competências em informação e responsabilidade social, o que representa um avanço para este campo científico. Observamos este avanço, numa perspectiva mais recente, em Righetto, Vitorino e Muriel-Torrado (2018, p. 77), que defendem que a abordagem social desta ciência é 
substancial, afinal os usuários da informação estão inseridos como indivíduos em mundos construídos socialmente, e não em mundos paralelos. Estes autores defendem, ainda, a pertinência da pesquisa social voltada às camadas vulneráveis da sociedade, sem perder de vista suas necessidades de informação, necessidades que podem e devem ser supridas com o desenvolvimento de competências em informação, que, para estes autores, é o "componente de emancipação cognitiva dos indivíduos".

Por fim, corroborando com Righetto, Vitorino e Muriel-Torrado (2018, p. 87), afirmamos que a Ciência da Informação e a Biblioteconomia têm a função social de promover cultura e democratizar o acesso à informação, mas que é preciso "reconhecer que os indivíduos possuem características e necessidades de informação distintas e que podem estar suscetíveis à vulnerabilidade", e isto "faz parte da responsabilidade social, profissional e científica" desse campo científico. Com base em todas essas premissas, fazse imprescindível e urgente o desenvolvimento de estudos sobre como as competências em informação, aliadas à responsabilidade social da biblioteca multinível, podem contribuir para a construção da cidadania através da socialização da informação. No contexto da biblioteca multinível, esses estudos são relevantes e atuais, devido a esse tipo de biblioteca ter como principal característica a ampla diversidade de usuários dos mais variados níveis de ensino e perfis socioculturais e econômicos diversos.

\section{CONSIDERAÇÕES FINAIS}

Investigação similar a esta foi realizada junto à BRAPCI, base de dados especializada em Ciência da Informação; porém, das 160 publicações que versam sobre responsabilidade social, nenhuma versa sobre esse tema em relação à biblioteca multinível. E mesmo sobre biblioteca multinível apenas duas publicações são recuperadas, e ambas são de nossa autoria, fruto do estudo realizado em nível de dissertação em 2015 e sem nenhuma correlação com responsabilidade/inclusão social.

Concordamos com Righetto, Vitorino e Muriel-Torrado (2018) que é preciso refletir sobre a criação de medidas para superar a vulnerabilidade social e a vulnerabilidade em informação, seja por meio da inclusão destes temas na formação acadêmica e nas práticas profissionais, ou por meio de ações, projetos e políticas públicas, a exemplo das políticas públicas de informação. 
Este estudo nos possibilitou ir além desta perspectiva. Com base no levantamento bibliográfico, na reflexão e em toda a discussão, podemos perceber a necessidade de trazer para a Ciência da Informação os desafios vivenciados na biblioteca multinível e nos IFs. O desenvolvimento de competências em informação poderá, neste contexto, contribuir para a diminuição, por exemplo, da evasão escolar e ainda possibilitar a inclusão educacional, o acesso ao mundo do trabalho e colaborar com a missão dessas instituições no sentido de formar cidadãos capazes de construir uma sociedade mais inclusiva, justa, sustentável e democrática.

É nesta perspectiva que os estudos vindouros devem se debruçar e empreender esforços. 0 fato de a literatura ainda ser incipiente, mais que um ponto negativo, constitui-se em uma oportunidade para a Ciência da Informação exercitar o seu lado social, desenvolvendo estudos e pesquisas que venham a contribuir com a inclusão social nestes novos espaços, que se fazem presentes e atuantes na sociedade brasileira.

0 artigo aponta ideias de estudos e pesquisas viáveis para o campo da Ciência da Informação numa perspectiva social, visando ao aperfeiçoamento da atuação da biblioteca multinível frente às questões de inclusão e a compreensão por parte da comunidade científica sobre o papel social da biblioteca multinível, seus desdobramentos e suas implicações teóricas e práticas na sociedade. Recomenda-se, portanto, a realização desta investigação para outras fontes além do Portal de Periódicos da CAPES, a saber, em bibliotecas de dissertações e teses, bases de dados especializadas em Ciência da Informação e nos periódicos científicos nacionais avaliados com Qualis A e B na área de Comunicação e Informação. Certamente os resultados serão outros e irão complementar este estudo e ampliar nosso conhecimento sobre a temática em questão.

Uma contribuição teórica que o presente estudo trouxe, a partir do mapeamento científico realizado, foi a evidenciação da necessidade e da possibilidade de se produzir uma rede conceitual que relaciona as políticas de informação com o desenvolvimento de competências em informação neste contexto de responsabilidade social da biblioteca multinível. Este será o nosso próximo passo, com base em Wersig (1993) e no aporte teórico até então encontrado na Ciência da Informação.

Este trabalho nasceu da relação entre um estudo que vem sendo desenvolvido para a tese de doutoramento e o conteúdo de uma disciplina curricular em nível de Doutorado em Ciência da Informação, e os resultados até então são profícuos. Ampliar a compreensão e o conhecimento acerca das políticas de informação neste contexto, 
relacionando-as diretamente às competências em informação, é um passo contínuo que deverá ser buscado nestes contextos de formação acadêmica e de desenvolvimento de pesquisas.

Apesar dos poucos trabalhos nesse viés temático, já é possível perceber os processos de inclusão e exclusão social que ocorrem nos Institutos Federais e, em especial, na biblioteca multinível, a exemplo: da oferta de cursos FIC e programas de educação para as comunidades de risco; da oportunidade de orientar o plano de carreira de jovens estudantes do ensino médio, ensino superior e pós-graduação; do desenvolvimento de competências em informação que pode se tornar uma ponte para inclusão digital e de promoção da cidadania; além de maior evidenciação da questão de acessibilidade, inclusão e exclusão em que a biblioteca indiscutivelmente está inserida. A responsabilidade social da biblioteca multinível é um desafio promissor para cientistas da informação e bibliotecários no século 21.

\section{REFERÊNCIAS}

ALMEIDA, J. L. S. de. A biblioteca como organização aprendente: o desenvolvimento de competências em informação no Instituto Federal de Educação, Ciência e Tecnologia da Paraíba. 2015. 123 f. Dissertação (Mestrado Profissional em Gestão nas Organizações Aprendentes) - Universidade Federal da Paraíba, João Pessoa, 2015.

ANTUNES, R. S. P.; SOUZA, G. F. M.; KLOSOSKI, S. J.; DIAS JÚNIOR, J. B.; FIGUEIRA, F. L. G. Análise do "Programa Mulheres Mil" no IFPR, Campus Paranavaí: a transformação social de mulheres em busca da igualdade de gênero.

Holos, ano 32, v. 1, p. 153-160, 2016.

BARDIN, Laurence. Análise de conteúdo. Lisboa: Edições 70, 1977.

BECKER, C. da R. F.; FAQUETI, M. F. Panorama das bibliotecas da Rede Federal de Educação Profissional, Científica e Tecnológica: um olhar sobre a gestão. Blumenau: IFC, 2015.

BEZERRA, A. S.; MARQUES, A. y C.; CIROLINI, A.; PAULUS, E.; MELLO, D. T. de. Perfil de estudantes do PROEJA Técnico em Comércio do
Instituto Federal Farroupilha - município de Júlio de Castilhos/RS em 2012. Regae: Rev. Gest. Aval. Educ., Santa Maria, v. 4, n. 8, p. 4150, jul./dez. 2015.

BRASIL. Lei no 11.892 de 29 de dezembro de 2008. Institui a Rede Federal de Educação Profissional, Científica e Tecnológica, cria os Institutos Federais de Educação, Ciência e Tecnologia, e dá outras providências. Diário Oficial [da] República Federativa do Brasil, Brasília, DF, 30 dez. 2008. Disponível em: http://pesquisa.in.gov.br/imprensa/jsp/visual iza/index.jsp?jornal=1\&pagina $=1 \&$ data $=30 / 12$ /2008. Acesso em 01 ago. 2018.

BRASIL. Ministério da Educação. Expansão da Rede Federal. Última atualização em: 21 set. 2018. Disponível em:

http://redefederal.mec.gov.br/expansao-darede-federal. Acesso em: 01 ago. 2018.

CORREA, M. P.; SILVA, J. A. F. Centro DidáticoPedagógico para o gerenciamento integrado de resíduos sólidos: estudo de caso para avaliação de viabilidade no Instituto Federal Fluminense - Campus Macaé, RJ-Brasil. Holos, ano 31, v. 6, p. $415-431,2015$. 
FREDENHAGEM, S.; COMETTI, N.; BONFIM, C. J. de L.; ARAÚJO, F. D. de. A voz da evasão. Eixo, v. 1, n. 2, 2012.

FREIRE, G. H. de A. Construção participativa de instrumento de política pública para gestão e acesso à informação. Perspectivas em Ciência da Informação, Belo Horizonte, v. 13, n. 3, p. 195-197, set./dez. 2008.

FURTADO, F.; ANTUNES, J. F.; SANTOS, L. M. M.; OLIVEIRA, L. A.; FERREIRA, R. S.; ALVES, B. M. M. Bem-estar subjetivo em participantes do Programa Mulheres Mil, na cidade de Barbacema-MG. Holos, ano 28, v. 4, 2012.

FURTADO, R. N. O.; OLIVEIRA, M. M. M. Construindo um modelo curricular integrado para a educação de jovens e adultos/formação inicial e continuada (EJA/FIC). Holos, ano 29, v. $5,2013$.

GARCIA, J. C. R.; BARBOSA, J. R.; OLIVEIRA, B. M. J. F. Biblioteca Pública Brasileira: identidades e cenário político gerencial. Percursos, Florianópolis, v. 12, n. 02, p. 106119, jul./dez. 2011.

GOMES, F. F. O processo educacional inclusivo no CEFET-RN: uma leitura crítica do projeto político-pedagógico. Holos, ano 24, v. 3, p. 3345, 2008.

HORA, L. C. A. Oportunidades de qualificação profissional fatiadas: as políticas focais e a formação dos trabalhadores. Revista

HISTEDBR On-line, Campinas, n. 65, p. 73-91, out. 2015.

LOPES, R. G.; MOURA, L. R. Responsabilidade socioambiental: uma análise do Projeto "Campus Verde - Gestão Ambiental do IFRN". Holos, ano 31, v. 3, p. 135-147, 2015.

MASCHIO, A. J. Mulheres Mil Binacional: relato de uma experiência única. Revista Thema, $\mathrm{v}$. 11, n. 2, p. 74-88, 2014.

MEDEIROS, L. C.; TABOSA, W. A. F. Percepção ambiental dos estudantes do curso técnico em alimentos do PROEJA no IFRN - Campus Currais Novos. Holos, ano 26, v. 3, 2010.
MOUTINHO, S. O. M. Práticas de leitura na cultura digital de alunos do ensino técnico integrado do IFPI- Campus Teresina Zona Sul. 2014. 183 f. Dissertação (Mestrado em Educação) - Universidade Vale do Rio dos Sinos, São Leopoldo, 2014.

PEREIRA, T. M. F. R. A.; GUEDES, S. S. Novo Tempo - a experiência de implantação do programa de preparação para o pós-carreira no IFRN. Holos, ano 28, v. 4, 2012.

RIGHETTO, G. G.; VITORINO, E. V.; MURIELTORRADO, E. Competência em informação no contexto da vulnerabilidade social: conexões possíveis. Inf. \& Soc.: Est., João Pessoa, v. 28, n. 1, p. 77-90, jan./abr. 2018.

SANTOS, C. A. S.; HOFFMANN, W. A. M.; BOCCATO, V. R. C. Os múltiplos olhares para as bibliotecas 102103 dos Institutos Federais de Educação, Ciência e Tecnologia. In: FÓRUM NACIONAL DE BIBLIOTECÁRIOS DOS INSTITUTOS FEDERAIS, 6., 2011, Petrolina. Anais [...]. Petrolina: Instituto Federal do Sertão Pernambucano, 2011.

SILVA JÚNIOR, A. S.; FRANCISCO JÚNIOR, W. E.; SILVA, J. C.; SILVA, J. M. Repensando a evasão escolar: uma análise sobre o direito à educação no contexto amazônico. Holos, ano 33, v. 2, 199-213, 2017.

TAVARES, C. B.; GOMES, M. L. M. "Projeto Educar para Ficar": ações que legitimam políticas afirmativas no âmbito da Rede Federal de Ensino. Vértices, Campos dos Goytacazes/RJ, v. 12, n. 3, p. 71-90, set./dez. 2010.

VERGARA, S. C. Métodos de pesquisa em administração. 4. ed. São Paulo: Atlas, 2010.

VITORETTE, J. M. B.; CASTRO, M. D. R. O programa de integração da educação profissional com a educação básica na modalidade de educação de jovens e adultos (PROEJA) no IFG Campus Goiânia: um percurso contraditório na construção do direito à educação. Holos, ano 32, v. 2, p. 301-311, 2016.

WERSIG, G. Information Science: The study of postmodern knowledge usage.

Information Processing and Management, v. 29, n. 2, p. 229-239, 1993. 